\title{
Improving Digital Image Quality for Convolution Neural Network Based Computer-Aided Diagnosis (CNN-CAD) of Skin Cancer
}

\author{
Tolga YALÇIN ${ }^{1}$ ORCID 0000-0001-6185-7559 \\ Amira TANDİROVIC GÜRSEL ${ }^{* 1}$ ORCID 0000-0002-9219-3203
${ }^{1}$ Adana Alparslan Turkes Science and Technology University, Electrical and Electronics Engineering Department, Adana

Geliş tarihi: 16.06.2021～Kabul tarihi: 10.12.2021

\begin{abstract}
Atıf şekli/ How to cite: GÜRSEL, A.T., YALÇIN, T., (2021). Improving Digital Image Quality for Convolution Neural Network Based Computer-Aided Diagnosis (CNN-CAD) of Skin Cancer. Çukurova Üniversitesi, Mühendislik Fakültesi Dergisi, 36(4), 1099-1110.
\end{abstract}

\begin{abstract}
The practice of detecting skin cancer is based primarily on a visual examination by a dermatologist, followed by a series of tests for a more accurate diagnosis. The concept "the earlier cancer is detected in its natural history, the more effective the treatment is likely to be" is also valid for skin cancer. Hence, any delayed or missed diagnosis can lead to a more severe clinical stage or, what's worse, death. On the other hand, the lack of biomarkers in clinical use brings about overdiagnosis and unnecessary biopsies.

DL-CAD system seems to be an excellent candidate for improving diagnostic accuracy and reducing unnecessary treatments. However, the vast majority of conventional CADs manipulate dermoscopic images, which require not only costly equipment but also time-consuming processing. Despite the difficulties with precision, state-of-the-art DL-CAD systems provide an interpretation using digital images, requiring no expertise in cost-effective dermoscopic image capture and interpretation. Preprocessing methods play a crucial role in solving this problem. This study presents results with regard to pre-processing steps to improve the images to be used in the diagnosis of the 5 most common skin cancer types for the proposed CNN based ResNet50 deep learning model. To the best of our knowledge it is the first time that ResNet50 deep-learning model has been utilized in diagnosis of skin cancer.
\end{abstract}

Keywords: Skin cancer, CNN-CAD systems, Dataset augmentation, Image pre-processing, Median filter

\footnotetext{
*Sorumlu yazar (Corresponding author): Amira Tandirovic Gursel, agursel@atu.edu.tr
} 


\section{Cilt Kanseri Teşhisi için Konvolüsyonel Sinir Ağları Tabanlı Bilgisayar Destekli Tanıda (CNN-CAD) Dijital Görüntü Kalitesinin İyileştirilmesi}

\section{$\ddot{\mathbf{O z}}$}

Cilt kanserini tespit edilmesi öncelikle bir dermatolog tarafından yapılan görsel muayeneye ve ardından daha doğru bir tanı için bir dizi teste dayanmaktadır. "Kanser doğal geçmişinde ne kadar erken tespit edilirse, tedavinin o kadar etkili olması muhtemeldir" kavramı cilt kanseri için de geçerlidir. Bu nedenle, gecikmiş veya kaçırılmış herhangi bir tanı daha ağır bir klinik aşamaya veya daha da kötüsü ölüme yol açabilir. Öte yandan, klinik kullanımda biyomarker eksikliği aşırı tanı ve gereksiz biyopsileri beraberinde getirmektedir.

DL-CAD sistemleri tanısal doğruluğu artırmak ve gereksiz tedavileri azaltmak için mükemmel bir aday gibi görünmektedir. Bununla birlikte, geleneksel CAD sistemlerin büyük çoğunluğu, yüksek maliyetli ekipmanın yansıra işlenmesi zaman alan dermoskopik görüntüleri kullanır. Hassasiyet hususundaki zorluklara rağmen, modern DL-CAD sistemleri, dijital görüntüleri kullanarak bir yorumlama sağlar ve uygun maliyetli dermoskopik görüntü yakalama ve yorumlamada uzmanlık gerektirmez. Ön işleme yöntemleri bu sorunun çözümünde çok önemli bir rol oynamaktadır. Bu çalışma, önerilen CNN tabanlı ResNet50 derin öğrenme modeli için en yaygın 5 cilt kanseri türünün teşhisinde kullanılacak görüntülerin iyileştirilmesine yönelik ön işleme adımlarına ilişkin sonuçları sunmaktadır. Bildiğimiz kadarıyla, cilt kanseri tanısında ResNet50 derin öğrenme modeli ilk kez kullanılmıştır.

Anahtar Kelimeler: Cilt kanseri, CNN-CAD sistemleri, Veri kümesi büyütme, Görüntü ön işleme, Medyan filtresi

\section{INTRODUCTION}

According to the latest annual report of the World Health Organization (WHO) as well as data sheets of Global Cancer Observatory (GCO), cancer, with about 10 million deaths in 2020 , is the second leading cause of death worldwide [1-2].Skin cancer, which is by far the most common cancer type regardless to gender, can be defined as the uncontrollable growth of abnormal cells due to permanent DNA damage in the outermost skin layer, epidermis[2]. The continued increase in prevalence of the skin cancer in the last decade is believed to be caused by factors such as prolonged and periodic exposure to UV radiation, changes in social habits, a decrease in the thickness of the ozone layer and climate changes [3-4] .

Skin cancers can be categorized as basal cell carcinoma of the skin (BCC), squamous cell carcinoma of the skin (SCC), melanoma skin cancer (MEL), Merkel cell carcinoma of the skin (MCC), lymphoma of the skin (LS) and Kaposi
Sarcoma (KS), according to the skin cell in which cancer develops. However, the most common categorization is the basic division into two groups: melanoma skin cancer (MEL) and nonmelanoma skin cancer (NMSC). Although BCC is a NMSC and one of the most common forms of skin cancer, MEL is more likely to grow and spread indirectly promoting higher mortality rates [5-6]. In the last decade, the number of patients diagnosed with newly invasive melanoma has increased by an average of $44 \%$. According to the American Cancer Society (ACS), it is estimated that more than 7 thousand people in the United States will die of melanoma skin cancer in 2021. Although the risk is in correlation with aging, with an average age of diagnosis of 65, melanoma is not uncommon in young adults, especially young women [7]. Relying on information from the SEER database providing survival statistics for different types of cancer, used by the ACS, it is to be pointed out that 5-year relative survival rates decrease from $99 \%$, for localized stage, to $27 \%$, for distant stage. Although it is underlined that 
these numbers don't take everything into account, there is no doubt the early detection and diagnosis play a crucial role in decreasing mortality [8-9].

Skin cancer detecting practice is predominantly based on a visual inspection by a dermatologist, followed by a series of tests to diagnose the disease. However, in several studies discussed about the accuracy of visual inspection alone addressing the high error rates it has been highlighted that diagnosis can be missed if visual inspection is used on its own [10]. It has been also pointed out that apart from improving the expertise of clinicians, this field should benefit more from new technologies and tools [11-12]. In this context, deep learning based computer aided (DLCAD) systems seem to be a great candidate for improving the diagnostic accuracy. Since the first conventional CAD system to be approved in mammography in 1998, these systems have made significant progress especially in the diagnostic imaging area. However, several challenges attributed to conventional CAD systems, such as high development costs, high rates of false positive ratings, and limitations to specific lesions, have hampered widespread access in clinical settings. State-of-the-art DL CAD systems seem to offer better solutions to these problems than their predecessors,

This paper, focused on image pre-processing methods and techniques for a Convolutional Neural Nework (CNN)-CAD system that is proposed to detect skin cancer, is organized as follows: Section 2 gives the general frame of the proposed model with valuable information about the dataset for the detection of skin cancer while Section 3 turns on the pre-processing methods for image filtering used in the study. In Section 4, we share the results obtained by pre-processing the digital images for the proposed CNN-CAD system. In Chapter 5, the shared results are discussed from the perspective of future studies.

\section{METHODOLOGY}

In the last decade, thanks to not only significant increase in our knowledge about human anatomy and physiology but also advances in computer technology as well as quite successful transference to the medical field, DL-CAD systems have become one of the most powerful assisting tools in diagnosis. Despite some challenges in precision, important features, such as the efficiency of image classification and object localization in images, have raised awareness of the great potential of DLCAD systems in early cancer diagnosis and created a fertile environment for multidisciplinary research [13-14]. Among several models for digital image classification CNN stays one step ahead primarily because of its ability to reduce the number of parameters it contains without losing the image quality.

Generally speaking, DL-CAD systems for diagnosing cancer, and melanoma is no exception, are recipes that consist of a few steps, and the output determines whether the area in the image looks suspicious. These steps can be ordered as follows: image capture, pre-processing, processing, classification, and declaration of results. Figure 1 shows a flow diagram of the proposed DL-CAD system during the training process, with important details related to the steps and highlighted pre-processing procedure.

Fulfilment of requirements largely depends on the proper functioning of the CAD system, which is not possible without a properly selected and defined dataset for training. Images available from data libraries on skin cancer of public image databases are basically categorized into two separate groups: dermoscopic and clinical (nondermoscopic) images. Dermoscopic images are obtained by examining skin lesions with a dermatoscope that allows the inspection of skin lesions with unobstructed reflections on the skin surface, while clinical images are digital images obtained by taking a photograph with any digital camera. Due to the higher image quality, dermoscopic images provide more accurate detection. However, disadvantages, such as expensive equipment and time-consuming processing as well as the requirement for interpretation by a dermatologist specialized in this field, are the major obstacles for wider applications. On the other hand, recent advances not only in digital image collection methods but also in post-processing techniques, bringing in 
flexibility in integration with some disruptive technologies, such as Artificial intelligence and health information system, have opened the door for low-cost real-time diagnosis. Naturally, digital imaging has become a hot topic for the scientific community. One of the important indicators of this attention is the growing presence of digital images in public databases.

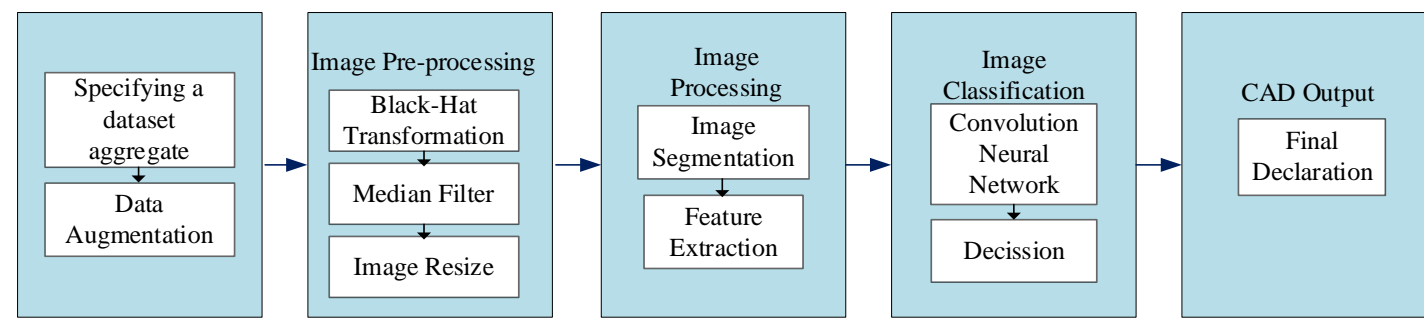

Figure 1. Flowchart of the proposed CAD system

The dataset of non-dermoscopic images used in this study, taken from The International Skin Imaging Collaboration (ISIC), was created for ISIC 2019 challenge [15-18]. As it shown in Figure 2, according to the type of disease the images can be divided into 8 categories: Basal cell carcinoma (BCC), Melanoma (MEL), Squamous cell carcinoma (SCC), Vascular lesion (VASC), Dermatofibroma (DF), Actinic keratosis (AK), Benign keratosis (solar lentigo / seborrheic keratosis/lichen planus-like keratosis) (BKL), and Melanocytic nevus (NV) [18-19]. It is to be noted that, BCC, MEL, and SCC are Cancerous tumours, while the others are Benign (Non-Cancerous) Tumours.

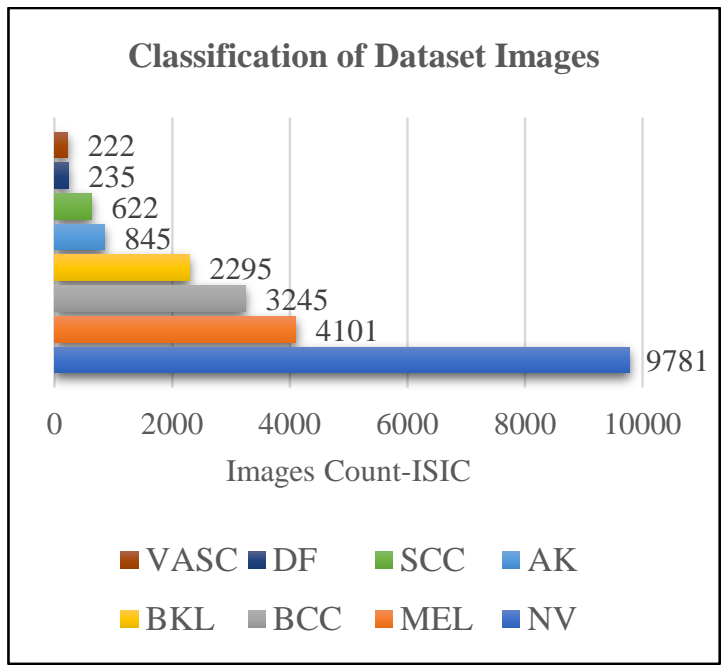

Figure 2. The classification of ISIC dataset
The difference in the representation of images in selected groups is one of the main training challenges resulting in sensitivity regarding representation weight affects the diagnosis accuracy. That is, the smaller groups are less likely to be predicted correctly. To settle this matter, we proposed a data augmentation algorithm that produces new images by modifying existing images. The procedure of obtaining new images, reaching up at least 5,690 images per group, is as follows: the algorithm selects the digital images from the group and rotates the image 180 degrees, before the image is restored to its original size by cutting the suspicious area at a rate of 0.1 from all sides and zooming in 0.1 as the centre. Image distributions of both the training set and testing set are represented in Table 1.

Table 1. Image distribution of datasets

\begin{tabular}{|l|c|c|c|c|}
\hline & NV & MEL & BCC & SCC \\
\hline Training Dataset & 7956 & 6037 & 6001 & 5690 \\
\hline Testing Set & 447 & 280 & 448 & 126 \\
\hline
\end{tabular}

\section{PRE-PROCESSING}

Despite numerous technical advantages, raw digital images are not suitable for usage in classification algorithms for cancer diagnosis. The main obstacles in direct using are: noise generated during the process and existing of multiple undesirable structures, such as air bubbles, and hair. The image enhancement is implemented through both image clearing, de-noising and 
resizing, for subsequent image analysis and understanding.

Adequate image pre-processing requires knowledge about skin cancer diagnosis. There are several important criteria to be taken into consideration in the selection of the image enhancement methods. First of all, the lesions related to skin cancer usually have small and sharp lines. The other important criterion is the colour of the lesion. Hence, characteristics such as colour variations and size of the image need to be preserved. On the other hand, the image resolution and sizing are required for future stages.

According to the research, there are several methods currently used for pre-processing in skin cancer diagnosis. Some of them are represented in [20-21]. In this study, we used one most popular ones, which can be defined through 3 steps: BlackHat transformation is used for hair removal, denoising and contrast enhancement are provided by Median Filter, while the image re-sizing is utilized to improve the quality and make all images one size.

\subsection{Black-Hat Transformation}

The difference image of the original image and its morphological closing refer to as black-hat operation and it is expressed mathematically as (Equation 1):

$T_{b}(f)=f \cdot b-f$

where, $f$ is the function of the original image, $b$ is a structuring element, and $\bullet$ is a closing operator. Separating and highlighting not only the objects smaller than structuring element but also the darker area from the area around the original outline, black-hat transform offers quite improved contours of the renderings.

The main reason why the Black-Hat method is preferred that after the cleaning process is done, a regional dyeing process is performed by adhering to the original colours of the digital image. BlackHat is a method used to remove hair from a digital image, by finding the hair in the image and replacing the hair with the colour values in the nearest pixels [21-22]. This pre-processing step is vital to ensure that the method used in the segmentation process makes satisfactory predictions.

\subsection{Median Filter}

Filters for noise cleaning have a very important place in image pre-processing. Regarding to image pre-processing for skin cancer detection, the filters commonly used are: Adaptive Median filter[22], Median filter[23],Gaussian smoothing[24], and Average filters[25]. Because, filtering can be viewed as a trade-off between improving the quality of the image and losing fine information, the filter is chosen or more often adapted according to the requirements for future applications. Among several aspects to be considered, the type of image, as well as the distribution of noise to be processed, are the most prominent ones. From a point of view of skin cancer detection, the applied filter has to protect the sharp edges in the same way while cleaning the digital image, predominantly degraded by salt-andpepper noise, which is non-linear in origin.

Apart from simple operation methodology, the median filter provides very fast and effective cleaning of some specific types of noise, as speckle and pepper noise, without damaging the edges of the digital image [26]. Since most skin cancers, especially melanoma, consist of nodule structures, some of the properties used to distinguish them are found in borders. Therefore, it is vital that border structures are protected without deterioration in order to make an accurate diagnosis. All of the aforementioned advantages make the median filter an appropriate candidate for de-noising. The basic working principle of the median filter is that it divides an image into pixels and works on all of them separately, replacing each pixel with the median of neighbouring pixels. Specifically, the median filter replaces just one neighbouring $(w)$ pixel using the median instead of the average of all pixels in a region (Equation 2);

$y[m, n]=\operatorname{median}\{x[i, j],(i, j) \in w\}$ 
where $w$ represents an area defined by the system or user and centered around the $[m, n]$ position [27].

As in order statistics, the input values of the current filter window are ranked in numerical order and a median value of those is assigned to the output cell. Since the median value is not affected by the actual value of the noise cells, the Median filter behaves as a nonlinear filter and is especially successful in removing isolated random noise making it preferable among the counterparts in this example. It should be emphasized that, although it retains the edges and features of the line better than either Average or Low-pass filter, the Median filter produces some blurring.

\subsection{Image Resize}

The images in the data set are of different sizes and resolutions and are usually i.e. 1024, 1024, 450, 600 etc. resolution. In order to make a healthy determination, it is important to reconstruct the dimensions and bring them to the same dimensions. First of all, the images cleaned from the hairs with the Black-Hat method were cleared of the images with the median filter, and finally, their size was changed to $224 \times 224$ and prepared for the processing stage. The reason for choosing these sizes is that while maintaining the large image quality, it has been tried to reduce it because large sizes cause the training phase of the program to be prolonged.

In the conclusion part, it is important to explain the following two concepts for a more detailed examination of the model. Recall can be briefly defined as follows: It is a metric that shows how much of the transactions we need to predict as positive as a result of classification, we predict as positive. It should be as high as possible (Equation 3).

FN=False Negative, TP=True Positive, FP=False Positive

Recall $=\frac{\mathrm{TP}}{\mathrm{TP}+\mathrm{FN}}$
The precision shows how many of the values we predicted as positive are actually positive. The precision value is a metric to be considered especially if the cost of returning the error made with false-positive estimation to you is very high Therefore, the high precision value of the model we will choose is an important criterion.

$$
\text { Precision }=\frac{T P}{T P+F P}
$$

\section{RESULTS}

This section is organized in the following order. In the first part, we present the results related to the process of obtaining new images for a data set. The second part of the section deals with image preprocessing, which is done in three steps: black-hat transformation, reconstruction by the Meridian filter, and resizing. At the end, in order to demonstrate the effectiveness of the proposed preparation of the image, we put forward training results with and without pre-processing. The results of the proposed data augmentation algorithm are represented in Figure 3. The original image is shown in Figure 3(a), while the images shown in Figure 3(b)-(d) represent the images obtained by proposed augmentation methods, explained in the methodology section.

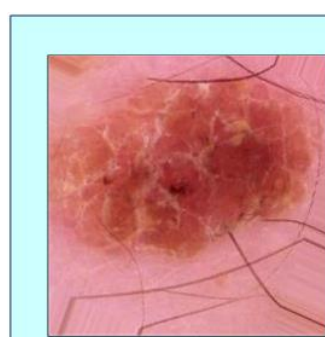

(a)

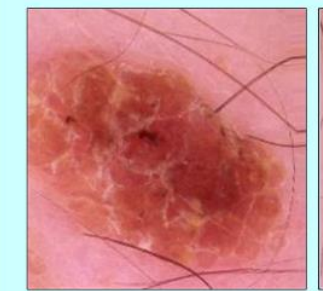

(c)

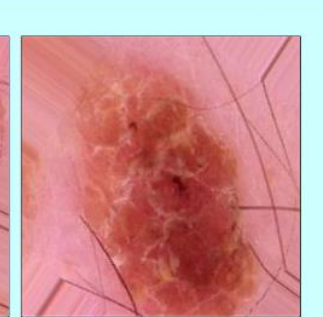

(b)

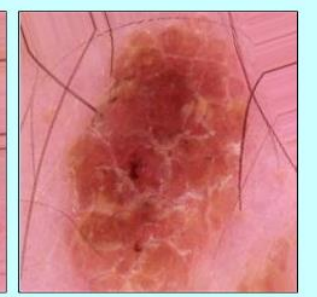

(d)
Figure 3. Examples of the proposed augmentation 


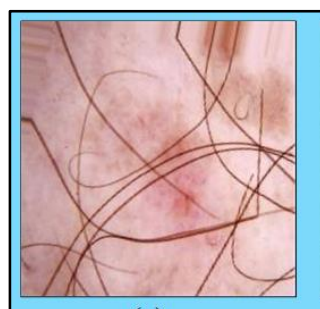

(a)

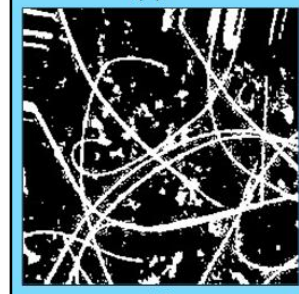

(d)

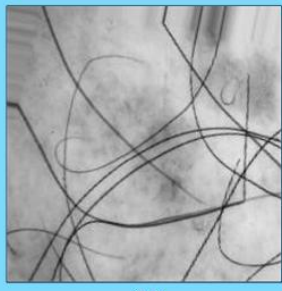

(b)

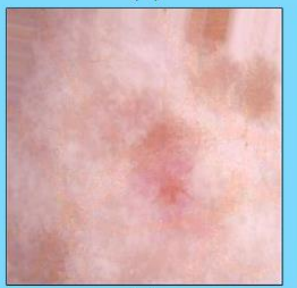

(e)

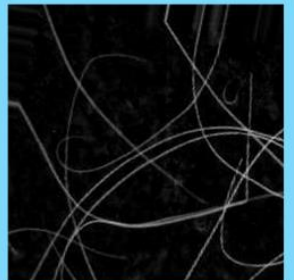

(c)

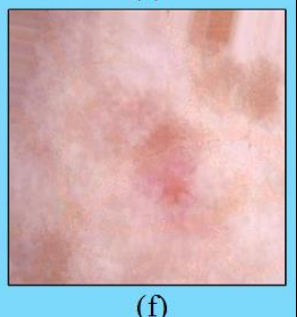

Figure 4. Black Hat Transformation and Image Filtering: (a) Raw image, (b) Grey-Scaling, (c) Black-Hat masking, (d)Image thresholding, (e) Re-Painting, (f) Image denoising by Median filter

Black-Hat method, the steps of which shown through Figure 4(a)-4(e), removes fine hairs in the image as follows: First, the original image is converted to grayscale (Figure 4(b)), which creates a core for Morphological filtering, using Black Hat filtering on the grayscale image to find the Hair contours. Effects of Morphological filtering on the images are presented in Figure 4(c). It prepares the image for the efficient and sharp operation of the in-painting algorithm by intensifying the lines in the area where the hairs are located, as it shown in Figure 4(d). Finally, Figure 4(e) represents results after the hairs are removed staining while the image remains true to its original colours. It is to be pointed out that enhance image is still blurred and contaminated by noise.

The median filter is not only very effective at removing small bubbles, noise contained in the image and pixels that are independent of other parts, but also preserves the spatial resolution in the image. Results related to image denoising by the median filter are shown in Figure 4(f). Comparing images of Figures 4(e) and 4(f), it can be said that the most salient differences between the two images are the softer transitions and evidently decrease in the number of white small dots, while the depth perception and colours are preserved.

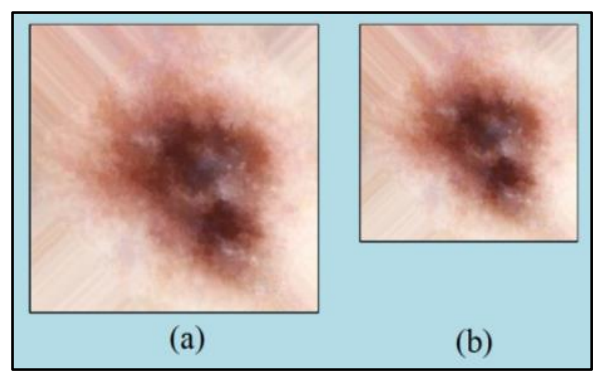

Figure 5. Resizing of the image: (a) Raw image, (b) Resized image

Finally, as it is fairly certain that image size diversity affects the algorithm accuracy, all images are resized to $224 \times 224$. Example resizing is shown in Figure 5, The image of Figure 5(a) where the image is 450x600 dimensions and 5(b) where original image resized to $224 \times 224$. In order to reveal the importance and necessity of preprocesses in digital image processing and classification programs, we wrote a CNN-based skin cancer identification algorithm, examining and classifying image dataset that consist of 4 groups named NV, BCC, SCC, MEL.

Applying the above-mentioned methods, we prepared the algorithm for training and obtained training and validation accuracies for the raw 
digital images as well as the pre-processed images. The results of training with the raw images are shown in Figure 6(a) to 6(b), while results represented in Figures 6(c) and 6(d) are related to accuracy and loss of the pre-processed images.

When raw digital images are used, our algorithm runs an average of 40 seconds slower for each epoch. This result may be negligible for small size operations However, when large data processing is required, it will not only create a huge load on the system but also force the systems to use more resources and energy. In today's world, energy efficiency and speed are undeniably important.

Additionally, from Figures 6(a)-6(b) it can be seen that use of the raw images lead to more unstable epoch, which is an important indicator of the unstable system. Also, the very high exchange between each epoch proves that it is an unstable and unhealthy system. In addition to this, it can be observed from Figure 6(c), which is pre-processed and uses digital data free from noise and pollution, is much better and more stable in the loss part as

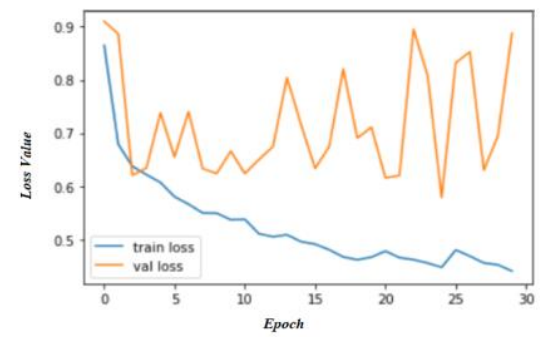

(a)

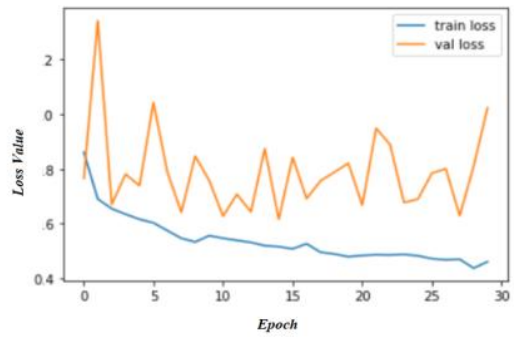

(c) well as working regularly. In machine learning, loss values are very important as well as accuracy. The reason for this is that the lost data shows us how stable it works actually and how efficiently it can read the data. Looking at it from this perspective, we can better understand the importance of pre-processing in digital data processing.

In order to obtain the performance of the proposed pre-processing methods on the sensitivity of the program according to the groups as well as to make more correct judgments on shortages of the proposed model, we formed a confusion matrix of the model. The two confusion matrices, shown in Figures 7(a) and 7(b), summarize results before and after the image pre-processing. Each row corresponds to the instances of an actual class, while each column represents an entry for a predicted class. Additionally, all correct predictions are located in a diagonal line, while off-diagonal cells correspond to incorrectly classified observations.

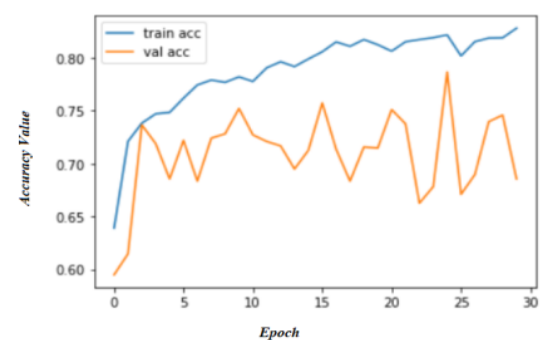

(b)

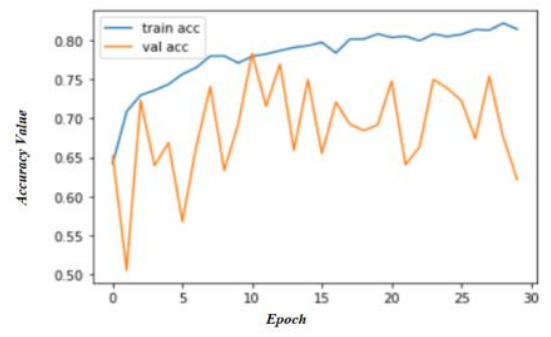

(d)

Figure 6. Training results: (a) The validation and training losses for each epoch with raw images. (b) The validation and training accuracy for each epoch with raw images. c) The validation and training losses for each epoch with pre-processed digital images (d) The validation and training accuracy for each epoch with pre-processed digital images 
Comparing the confusion 1 matrices, it can be said that, from the general point of view, training with pre-processed images makes a more stable and accurate prediction. That is to say, suppressing the noise and getting rid of hairs found in digital images at one and the same time adjusting the sharpness of the shape and the colour gradations increases the selectivity to malign images. According to the proposed groups, in both matrices, the best accuracy is achieved for $\mathrm{NV}$ whereas the poorest results are recorded for SCC. Moreover, in all groups except SCC, there is undoubtedly a positive impact of the preprocessing. However, it is to be pointed out that, in both cases, both BCC and MEL are the most frequently confused with SCC. The main reason for the confusion is a lot of structural similarities between those groups. This problem will be solved by giving better prominence to determinant differences of the groups during the processing procedure. Although the accuracy rates of our model are still poor for usage in daily life, it should be remembered that pre-processing is not a final procedure. Its real purpose is to prepare the images for the next stage, to speed up not only the training but also the decision-making period, as well as increase efficiency and precision.

The sensitivity and precision results are shown in the tables below. When looking at the total results, we can observe that the model trained using preprocessed pictures produces better outcomes in both categories. When examining the model in depth on the basis of groups, can see that the model is more stable and the transition between groups is more balanced as a result of the preprocessed images.

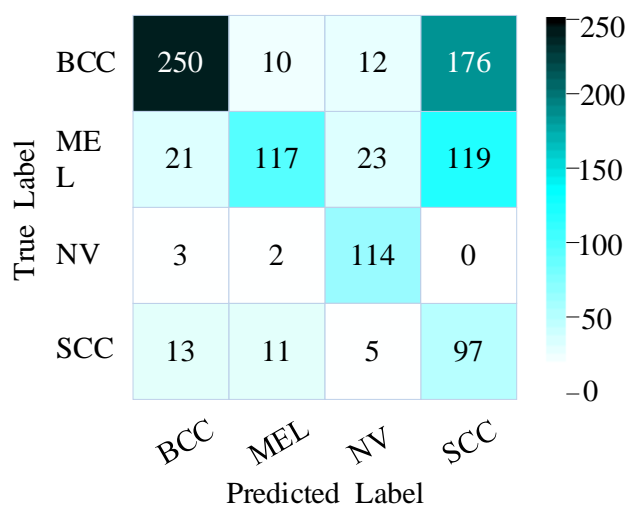

(a)

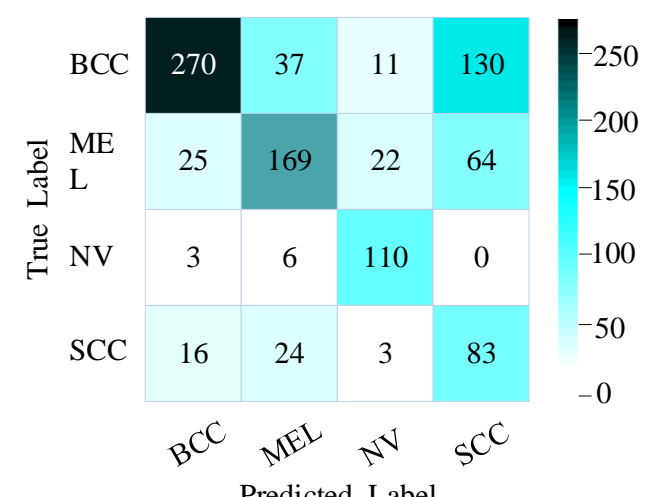

(b)

Figure 7. Confusion matrices

\begin{tabular}{|c|l|l|c|c|c|}
\hline $\begin{array}{c}\text { Pre-Processed } \\
\text { Image } \\
\text { ModelResults }\end{array}$ & RECALL & PRECISION & $\begin{array}{c}\text { Raw Image } \\
\text { ModelResults }\end{array}$ & RECALL & PRECISION \\
\hline BCC & 0.6028 & 0.8698 & $B C C$ & 0.5580 & 0.8710 \\
\hline MEL & 0.6035 & 0.7524 & MEL & 0.4178 & 0.8357 \\
\hline NV & 0.9258 & 0.7534 & NV & 0.9579 & 0.7402 \\
\hline SCC & 0.6642 & 0.30 & SCC & 0.77 & 0.1509 \\
\hline$\underline{\text { Total }}$ & 0.6990 & 0.6689 & $\underline{\text { Total }}$ & 0.6759 & 0.6494 \\
\hline
\end{tabular}

Figure 8. Precision and Recall tables 


\section{CONCLUSION}

Advantages, such as less reliance on feature extraction, direct learning from input data, less need for consistent equalization engineering, and, the most important, utilizing digital images, make CNN-CAD systems powerful candidates in skin cancer diagnosis. In comparison to dermoscopic images, digital images offer lower-costs and lesscomplex systems. However, digital images suffer from various types of noise, which affects the accuracy of proposed models. Hence, there is a strong requirement for less-noisy digital images with well-preserved edges, which are of vital importance in distinguishing melanoma from benign tumours as well as other cancer types.

Up to now, the CADs systems have employed primarily 2-group or 3-group classifications. In the two-group classification, the digital images are classified as cancer or not, while the three-group classification groups the images as melanoma cancer, non-melanoma cancer, and non-cancer. The proposed CADs system not only increases the number of classes to four but provides a good basis for more exhaustive classification.

There have been several research studies on the relevance of pre-processing for image analysis, but none have specifically addressed the skin cancer group. Unlike the others, no Feature Extraction was done while classifying in this research since the purpose is to investigate the influence of preprocessed pictures on classification outcomes. As a consequence, the study's accuracy findings may appear to be low, but it should be noted that the major goal here is to assess the influence of raw pictures and pre-processing images on the system.

This study provides a comprehensive look at the preparation for processing and analysis of digital images for CNN-CAD proposed for the detection of skin cancer. The process starts with augmentation of the dataset which, providing more extensive training, may help to reduce falsepositive and false-negative rates.

Fit for purpose, we multiplied the images in the data set according to certain rules to bring the number of images in the groups to a certain average. The noise of the proposed digital images mainly manifests itself through hair sounds, white or blue light, or interference with the main source of which the image captured. We try reducing their negative impacts by pre-processing digital images of the public dataset. For the above reasons, we removed hair, unwanted features, and errors during recording using the Black-Hat filter, and in the next step, the sounds within the digital images were destroyed using the median filter. The last issue to be considered in the pre-processing procedure is image equalization. We proposed an adaptive algorithm for reducing all images in size, to avoid errors that could occur due to different image sizes and qualities in the data set.

Our future study will be focused not only on improving both pre-processing and extraction features from digital images, collected from several local hospitals, but also on evolving up the more inclusive algorithm.

\section{REFERENCES}

1. World Health Organization. 2021. WHO Report on Cancer: Setting Priorities, Investing Wisely and Providing Care for All. (Second Edition), Geneva, Wiley.

2. Atlanta American Cancer Society, 2021, Cancer Facts Figures 2021. Atlanta, USA, 13-15.

3. Global Burden of Disease Cancer Collaboration and Others. 2019. Global, Regional, and National Cancer Incidence, Mortality, Years of Life Lost, Years Lived with Disability, and Disability-adjusted Life-years for 29 Cancer Groups, 1990 to 2017: a Systematic Analysis for the Global Burden of Disease Study. JAMA Oncology; 5, 1749-1768.

4. Khazaei, Z., Sohrabivafa, M., Mansori, K., Naemi, H., Goodarzi, E., 2019. Incidence and Mortality of Cervix Cancer and Their Relationship with the Human Development Index in 185 Countries in the World: An Ecology Study in 2018. Advances in Human Biology, 9(3), 222-227. 
5. Avanaki, M.R.N., Hojjat, A., Podoleanu, A.G., 2009. Investigation of Computer-based Skin Cancer Detection Using Optical Coherence Tomography. Journal of Modern Optics, 56(13), 1536-1544.

6. Mohan, S.V., Chang, A.L.S., 2014. Advanced Basal Cell Carcinoma: Epidemiology and Therapeutic Innovations. Current Dermatology Reports, 3(1), 40-45.

7. Atlanta American Cancer Society. 2020. Cancer Facts Figures 2020. Atlanta, USA, 10-14.

8. MacFarlane, D., Shah, K., Wysong, A., Wortsman, X., Humphreys, T.R., 2017. The Role of Imaging in the Management of Patients with Nonmelanoma Skin Cancer: Diagnostic Modalities and Applications. Journal of the American Academy of Dermatolgy, 76(4), 579-588.

9. Rat, C., Hild, S., Serandour, J.R., Gaultier, A., Quereux, G., Dreno, B., Nguyen, J.M., 2018. Use of Smartphones for Early Detection of Melanoma: Systematic Review. Journal of Medical Internet Reseach, 20(4), 135-140.

10. Dinnes, J., Deeks, J.J., Grainge, M.J., Chuchu, N., Ferrante di Ruffano, L., Matin, R.N., Thomson, D.R., Wong, K.Y., Aldridge, R.B., Abbott, R., Fawzy, M., Bayliss, E.E., Takwoingi, Y., Davenport, C., Godfrey, K., Walter, F.M., Williams, H.C., Cochrane Skin Cancer Diagnostic Test Accuracy Group, 2018. Visual Inspection for Diagnosing Cutaneous Melanoma in Adults. Cochrane Database System Review, 12(12), 1689-1699.

11. Fujita, H., 2020. AI-based Computer-aided Diagnosis (AI-CAD): the Latest Review to Read First. Radiological Physics and Technology, 13(1), 6-19.

12. Cetinkaya, E., Kirac, M.F., 2020. Image Denoising Using Deep Convolutional Autoencoder with Feature Pyramids. Turkish Journal of Electrical Engineering \& Computer Sciences, 28, 2096-2109.

1. Ebigbo, A., Mendel, R., Probst, A., Manzeneder, J., Souza Jr, L.A., Papa, J.P., Palm, C., Messmann, H., 2019. Computeraided Diagnosis Using Deep Learning in the
Evaluation of Early Oesophageal Adenocarcinoma. Gut, 68(7), 1143-1145.

13. Yanase, J., Triantaphyllou, E., 2019. A Systematic Survey of Computer-aided Diagnosis in Medicine: Past and Present Developments. Expert Systems with Applications, 138, 112-821.

14. Codella, N.C.F., Gutman, D., Celebi, M.E., Helba, B., Marchetti, M.A., Dusza, S.W., Kalloo, A., Liopyris, K., Mishra, N., Kittler, H., Halpern, A., 2018. Skin Lesion Analysis Toward Melanoma Detection: A Challenge at the 2017 International Symposium on Biomedical Imaging (ISBI), Hosted by the International Skin Imaging Collaboration (ISIC). IEEE $15^{\text {th }}$ International Symposium on Biomedical Imaging, Washington DC, USA, 168-172.

15. Tschandl, P., Rosendahl, C., Kittler, H., 2018. The HAM10000 Dataset, a Large Collection of Multi-source Dermatoscopic Images of Common Pigmented Skin Lesions. Scientific Data, 5, 1-9.

16. Combalia, M., Codella, N.C.F., Rotemberg, V., Helba, B., Vilaplana, V., Reiter, O., Carrera, C., Barreiro, A., Halpern, A.C., Puig, S., Malvehy, J., 2019. Dermoscopic Lesions in the Wild, 1908.02288.

17. Vasconcelos, C.N., Vasconcelos, B.N., 2020. Experiments Using Deep Learning for Dermoscopy Image Analysis, Pattern Recognition Letters, 139, 95-103.

18. Steppan, J., Hanke, S., 2021. Analysis of Skin Lesion Images with Deep Learning. arXiv preprint arXiv:2101.03814. 2021, 06.06.2021.

19. Vocaturo, E., Zumpano, E., Veltri, P., 2018. Image Pre-processing in Computer Vision Systems for Melanoma Detection. 2018 IEEE International Conference on Bioinformatics and Biomedicine, Madrid, Spain, 2117-2124.

20.Zghal, N.S., Derbel, N., 2020. Melanoma Skin Cancer Detection Based on Image Processing. Current Medical Imaging Reviews, 16(1), 50-58.

21. Hoshyar, A.N., Al-Jumaily, A., Hoshyar, A.N., 2014. The Beneficial Techniques in Preprocessing Step of Skin Cancer Detection System Comparing. Procedia Journal of Computational Science, 42, 25-31. 
22. Tan, T.Y., Zhang, L., Jiang, M., 2016. An Intelligent Decision Support System for Skin Cancer Detection from Dermoscopic Images. IEEE $12^{\text {th }}$ International Conference on Natural Computation, Fuzzy Systems and Knowledge Discovery, Changsha, China, 2194-2199.

23. Sheha, M.A., Mabrouk, M.S., Sharawy, A., 2012. Automatic Detection of Melanoma Skin Cancer Using Texture Analysis. International Journal of Computer Mathematics, 42(20), 22-26.

24. Mishra, N.K., Celebi, M.E., 2016. An Overview of Melanoma Detection in Dermoscopy Images Using Image Processing and Machine Learning, arXiv preprint arXiv:1601.07843.

25. Rhee, K.H., 2017. Median Filtering Detection Based on Variations and Residuals in Image Forensics. Turkish Journal of Electrical Engineering \& Computer Sciences, 25, 3811-3826.

26. Jana, E., Subban, R., Saraswathi, S., 2017. Research on Skin Cancer Cell Detection Using Image Processing. IEEE International Conference on Computational Intelligence and Computing Research, Tamil Nadu, India, 1-8. 